\title{
Incorporating Applied Undergraduate Research in Senior to Graduate Level Remote Sensing Courses
}

\author{
Richard B. Henley ${ }^{1}$, Daniel R. Unger ${ }^{1}$, David L. Kulhavy ${ }^{1} \&$ I-Kuai Hung ${ }^{1}$ \\ ${ }^{1}$ Arthur Temple College of Forestry and Agriculture, Stephen F. Austin State University, Nacogdoches, Texas, U.S.A. \\ Correspondence: Daniel R. Unger, Arthur Temple College of Forestry and Agriculture, Stephen F. Austin State \\ University, Nacogdoches, Texas, U.S.A. Tel: 1-936-468-3301
}

Received: December 15, 2015

Accepted: January 6, 2016

Online Published: January 12, 2016

doi:10.5430/ijhe.v5n1p232

URL: http://dx.doi.org/10.5430/ijhe.v5n1p232

\begin{abstract}
An Arthur Temple College of Forestry and Agriculture (ATCOFA) senior spatial science undergraduate student engaged in a multi-course undergraduate research project to expand his expertise in remote sensing and assess the applied instruction methodology employed within ATCOFA. The project consisted of performing a change detection land-use/land-cover classification for Nacogdoches and Angelina counties in Texas using satellite imagery. The dates for the imagery were spaced approximately ten years apart and consisted of four different acquisitions between 1984 and 2013. The classification procedure followed and expanded upon a series of concrete theoretical remote sensing principles, transforming the four remotely sensed raster images into corresponding classified vector maps. The progression of the research project is layed out in a step-by-step process identifying settings and addressing issues that may commonly be encountered. The results indicate that the digital imagery acquired by the Landsat 8 sensor may have resulted in more precise and consistent spectral recognition of the image pixels, and distributed them more accurately in their clusters. The results from the study validate the applied instruction methodology employed in the remote sensing curriculums and reinforce ATCOFA's mission by guiding and empowering undergraduate students with the capability of employing sophisticated remote sensing technology to accurately quantify, qualify, map, and monitor natural resources.
\end{abstract}

Keywords: Land-use/Land-cover, Image classification, Landsat, Forests, Remote sensing

\section{Introduction}

The goal of science is to discover universal truths that are the same yesterday, today, and tomorrow. Hopefully, the knowledge obtained can be used to protect the environment and improve human quality of life. During the past century, considerable efforts have been placed into the development and advancement of satellite sensors that can collect information some remote distance from a subject to aid in obtaining that knowledge; a process referred to as remote sensing of the environment (Jensen, 2005). Remote sensing is characterized as the process of obtaining information about the Earth's surface from a distance based on electromagnetic energy. Remote sensing generally consists of utilizing aerial photography or remotely sensed digital satellite imagery to quantify and qualify natural resources (Campbell \& Wynne, 2011). A land-use/land-cover (LUC) classification provides a significant component in the processes of remote sensing and the science of changes in landscapes (He, Sun, Xu, Wang, \& Hu, 2014). The output derived from analyzing remotely-sensed data can contribute reliable information, potentially invisible to the naked eye, for socio-related roles such as city planners, analysts, and natural resources management entities. Remote sensing provides an avenue for observing small and large-scale changes on the Earth's surface using detected spectral differences in the energy reflected or emitted from features of interest.

\subsection{Remote Sensing within Natural Resources Curriculums}

Arthur Temple College of Forestry and Agriculture (ATCOFA) undergraduate students at Stephen F. Austin State University (SFA) focus on applying the use of remote sensing for the purpose of natural resources management (Kulhavy, Unger, Hung, \& Douglass, 2015). The mission statement of ATCOFA is to maintain excellence in teaching, research and outreach to enhance the health and vitality of the environment through sustainable management, conservation, and protection of natural resources. The college is devoted to comprehensive education at undergraduate and graduate levels, basic and applied research programs, and service (Bullard, Stephens Williams, Coble, Coble, Darville, \& Rogers, 2014). In order to effectively attain the mission statement, undergraduate remote 
sensing coursework within ATCOFA focuses on traditional classroom and laboratory instruction combined with a heavy emphasis on integrating hands-on instruction in a rigorous setting via one-on-one faculty collaboration, to produce a more accomplished and competent graduate (McBroom, Bullard, Kulhavy \& Unger, 2015). Students studying and learning remote sensing courses, at ATCOFA, focus on hands-on instruction and real-world applications using the most current geospatial and remote sensing technology (Unger, Kulhavy, Hung, \& Zhang, 2014).

A focus of hands-on instruction is vital to a student's success and mastery of both the theoretical and applied attributes of remote sensing. ATCOFA reinforces that remote sensing can provide an essential observation instrument in the fields of forestry and natural resources management. Within ATCOFA, there are specific courses that focus on training undergraduate students in remote sensing and how to use aerial photographs and remotely sensed digital imagery. The remote sensing methods are used in association with geographic information systems (GIS) to quantify, qualify, map, and monitor natural resources to solve problems, issues, and concerns that natural resource managers address on a daily basis (Kulhavy, Unger, Williams, \& Jamar, 2015).

\subsection{Study Objectives}

Nacogdoches and Angelina counties have a longstanding reputation as containing and contributing large amounts of the timber in east Texas that is managed and harvested. According to the Forest Inventory and Analysis Report of United States Department of Agriculture (USDA) Forest Service (Rosson, 2000), there was a total increase of 202,700 acres of timberland between 1986 and 1992 in east Texas (Hung, Williams, Kroll, \& Unger, 2004). An ATCOFA senior spatial science undergraduate student initiated a multi-course project, with the assistance of ATCOFA faculty, by conducting undergraduate research designed to: (1) expand his understanding of remote sensing by learning how to perform a change detection LUC classification using remotely sensed satellite data; (2) generate a reliable process for conducting such a project; (3) troubleshoot and address any errors encountered during the procedure; and (4) quantify the land areas of the study location using the data derived from the LUC classification. The overall objective of this endeavor was to develop remotely sensed maps illustrating the LUC changes in Nacogdoches and Angelina counties, at decade intervals, between 1984 and 2013 in order to evaluate the LUC trends that have taken place during the specified time frame.

\section{Methods}

\subsection{Study Location}

The study areas for this remote sensing evaluation are Nacogdoches and Angelina counties, of Texas, which are illustrated in Figure 1 below.

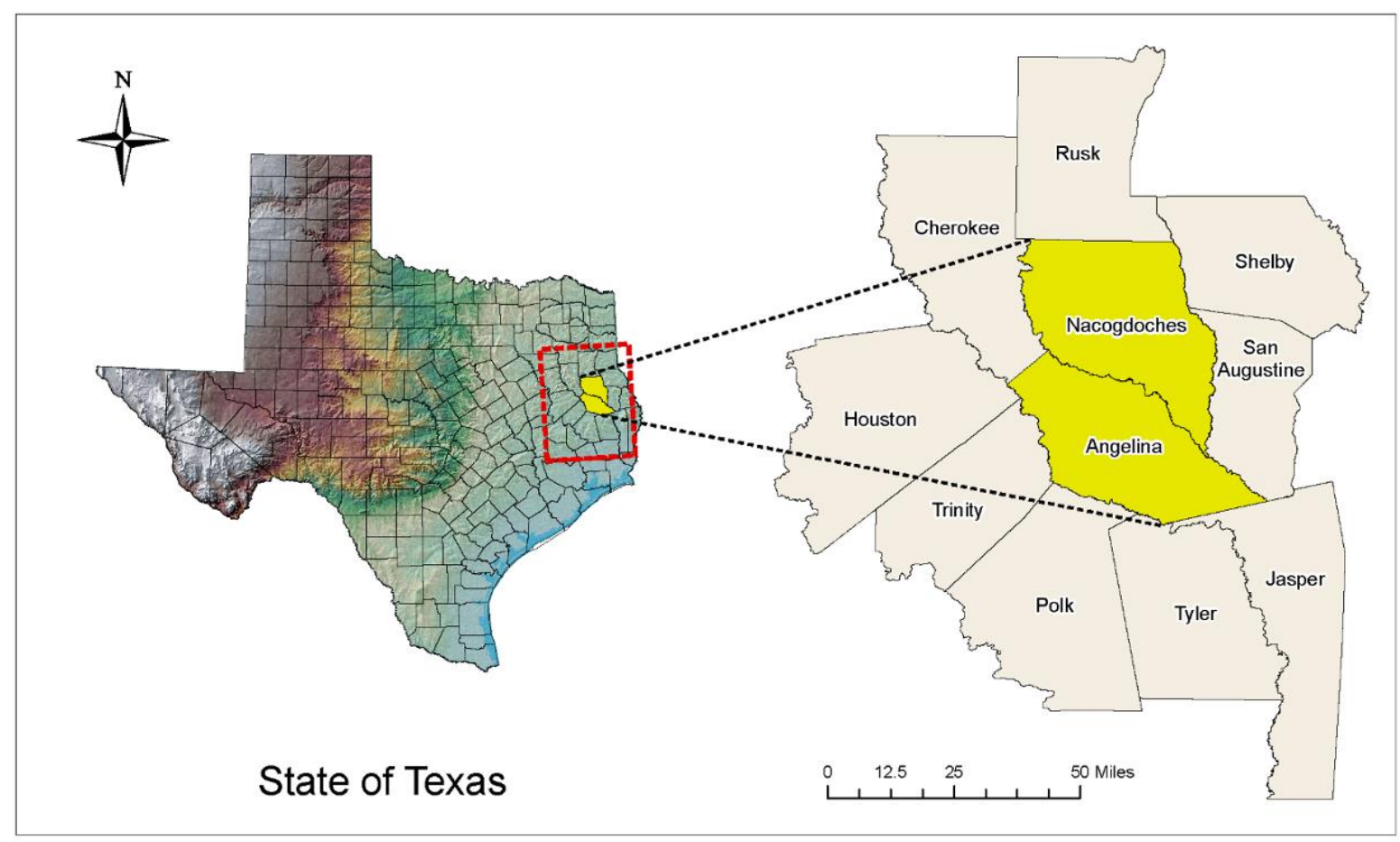

Figure 1. The location of Nacogdoches and Angelina Counties in Texas 
There are multiple attributes associated with Nacogdoches and Angelina counties being selected as the primary areas of interest (AOI). One reason is due to the close proximity and historical connections that the two counties share (Owojori, 2003). Secondly, both of the largest cities within the two counties are comparable in population, with Nacogdoches (Nacogdoches county) containing a population of 33,687 and Lufkin (Angelina county) containing a population of 36,141 according to the U.S. Census Bureau 2014 estimate.

\subsection{Coursework Analysis}

Undergraduate remote sensing course work within ATCOFA focuses on traditional classroom instruction and relies heavily on integrating hands-on instruction via one-on-one faculty interaction within a computerized environment to produce a more accomplished and competent graduate, as depicted in Figure 2 (Unger, 2014). The GIS faculty within ATCOFA are pleased with the fact that they devote one-on-one time with each individual student to maximize their learning potential. Students within ATCOFA obtain hands-on instruction daily using top-of-the-line GIS computer facilities with cutting edge spatial science and remote sensing software, necessary for succeeding in the execution of remote sensing research and productivity.

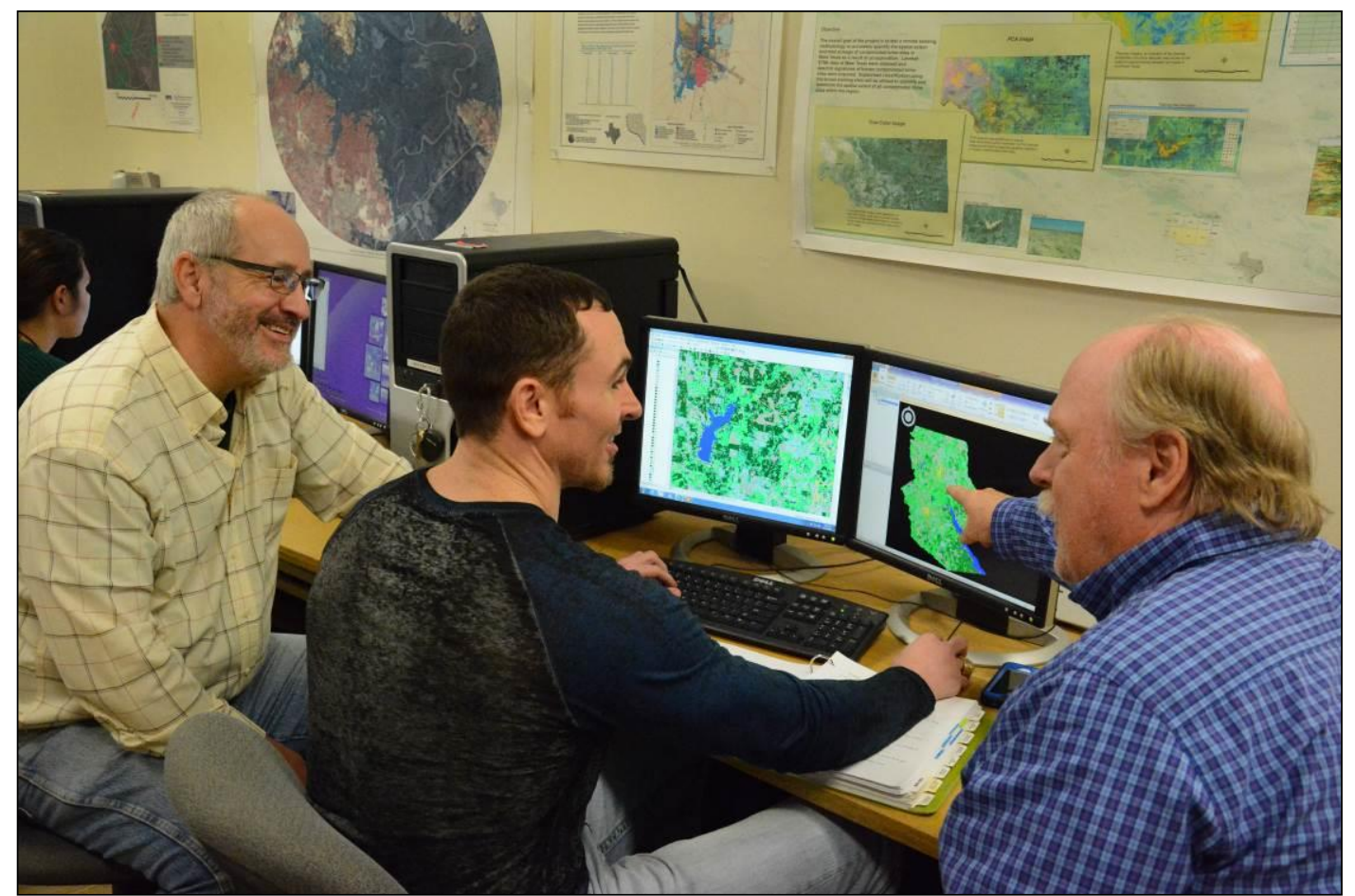

Figure 2. GIS faculty interacting one-on-one with an undergraduate spatial science student in the ATCOFA GIS Lab

The undergraduate student participated in four essential ATCOFA courses with the expectation of learning the theories and appropriate techniques needed in order to successfully conduct a two-county remote sensing research project. Instructed by Dr. Daniel Unger, Remote Sensing Applications was a course that concentrated on the analysis of remote sensing application methods applied to digital data involved with mapping, monitoring and managing environmental resources. Techniques involved with enhancement and analysis for both data visualization and processing were thoroughly explored. The student demonstrated proficiency in understanding how to apply imagery data involved with the mapping, monitoring and management of natural resources and how to present his findings in a map product. The student learned how to map, monitor and manage natural resources in a production oriented environment using contrast enhancement techniques, filter enhancement techniques, mathematical ratios, image merging, change detection algorithms, spatial modeling, thermal data, topographic analysis and spatial data conversion. The course Landscape Modeling, instructed by Dr. David Kulhavy, was designed to emphasize the application of GIS used for solving and managing spatial applications for natural and cultural resources. The course required the student to develop formulations, calculations, writings and implementations of multiple-use spatial management for natural resource and cultural resources. The student also gained an in-depth examination of the specific processes related to the scope of the remote sensing project by joining a graduate level course titled Digital Remote Sensing, also instructed by Dr. Daniel Unger. The course offered an introduction to the theoretical and 
practical applications of digital remote sensing for natural resource management; specifically including a history and overview of remote sensing, the electromagnetic spectrum, image acquisition, image classification and accuracy assessment. The fourth course, directed by Dr. David Kulhavy, was a senior level capstone course titled Ecological Planning that integrated rudiments from prerequisite courses. The concentration of Ecological Planning was for faculty to culminate one-on-one instruction with the students in order to complete a real-world research project integrating both laboratory and field data that represents their mastery of spatial science technology.

The student gained knowledge, expertise and critical thinking skills from each of the significant courses which were then validated through the execution of the two-county remote sensing project. After formulating the bounds of the research project the undergraduate student was first instructed where and how to collect the data required for accomplishing the project. After compiling the data the undergraduate student was instructed how to appropriately implement radiometric corrections to the imagery used during the research project. Once the student revealed to the GIS faculty his mastery of visual interpretation, he then begins the timely LUC classification process for each of the imagery anniversary dates. After the student completed the classification process he performed the post-classification and compiled a summary report for each of the project imagery anniversary dates.

\subsection{Change Detection}

Change detection consists of time-based phenomena demonstrated in imagery from multiple dates that is acquired through satellite multispectral sensors located in outer space. Change detection in remote sensing is important to natural resource management because it provides a broad perspective on landscapes and over time can reveal consistency or change. Therefore, change detection can provide an enlightening avenue for monitoring and managing protected areas, magnifying phenological concerns for particular regions, and quantifying trends such as urbanization. Change detection concerning forest ecosystems can reveal critical events that may be occurring without an evident change to natural resources managers. Examples may include excessive timber harvesting, land clearing, diseases and insects, or natural regeneration.

Biophysical resources and human-made features on the surface of Earth can be inventoried using remote sensing techniques. Some of the data are somewhat static, remaining constant over time; however, many biophysical materials and human-made features are dynamic, fluctuating rapidly. One important aspect to consider in change detection is the time period. It is necessary to select the appropriate time frame for each change detection and refrain from being overly ambitious in an attempt to monitor changes of a landscape. Natural ecosystems go through repeatable, foreseeable progressions of development. Human beings regularly are involved in modifying the landscape in repeatable, foreseeable stages. These phases of probable development are often referred to as phenomenological or phenological cycles. Vegetation matures according to fairly predictable diurnal, seasonal, and annual phenological cycles. Urban-suburban landscapes also are subject to phenological cycles. Therefore, obtaining near-anniversary images significantly minimizes the effects of seasonal phenological variances that may cause misleading change to be detected in the imagery. The time periods for this study continues a trend from previous LUC classification studies for the AOI and are separated by approximately ten years between data acquisition dates. The selection of this time period provides the appropriate number of seasonal rotations throughout the landscape in conjunction with delicately moderating other aspects of change, such as urban development, into the LUC results. One of the ultimate benefits provided from the corresponding change detection is quantitative LUC over the denoted period of time, allowing for a thorough acreage assessment of the classification types.

\subsubsection{Change Detection Workflow}

A series of sequential steps are required in order to complete a successful remote sensing change detection study. For this change detection analysis, the schematic in Figure 3 illustrates the steps that were taken by the student in order to achieve the end results: 


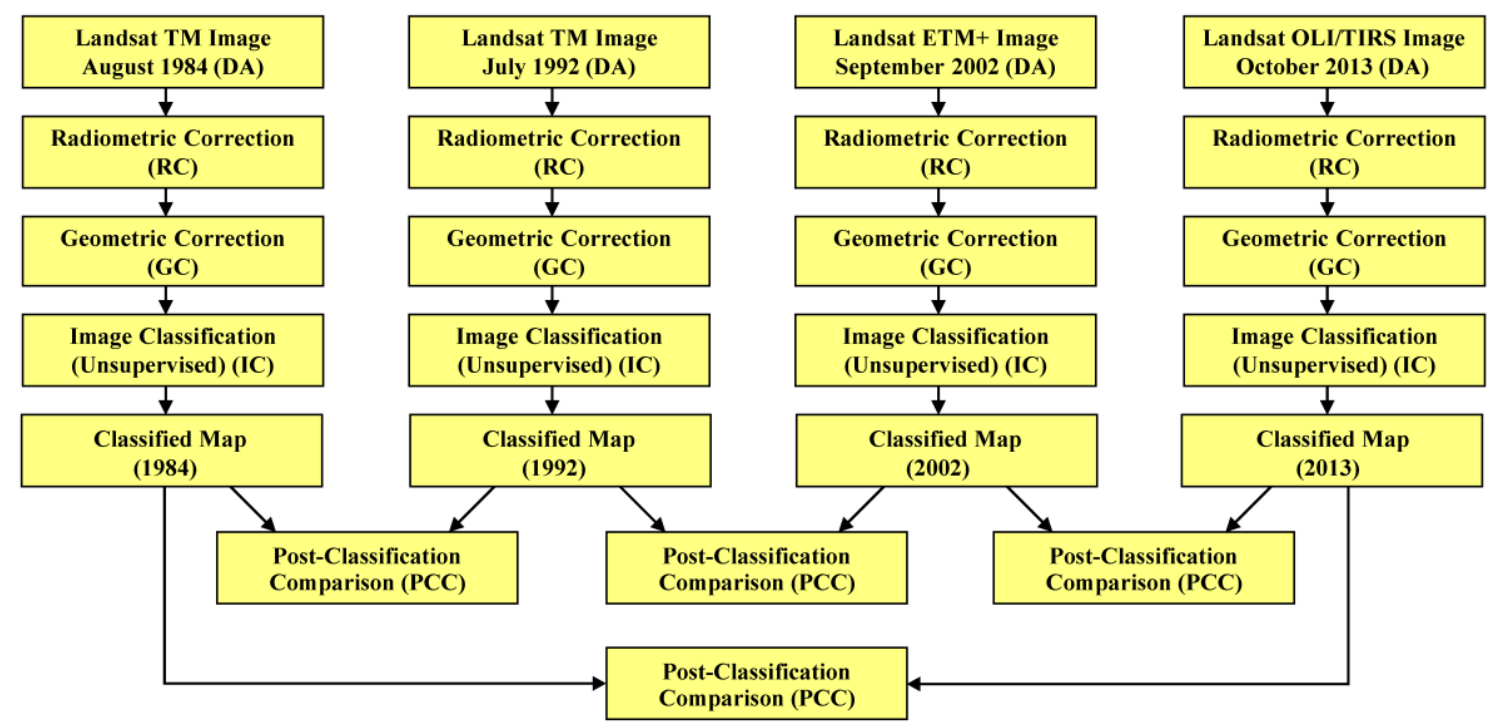

Figure 3. Change detection schematic workflow process

The change detection process uses satellite sensors to detect biophysical changes over time at the same location or locations, on a pixel-by-pixel basis. For practical reasons the change detection should maintain consistent anniversary date intervals for the classification of each subject scene.

\subsubsection{Satellite Imagery Acquisitions}

The satellite acquisition dates and sensors for the images used in this project were: (1) August 17, 1984 - Landsat 5 TM (2) July 6, 1992 - Landsat 5 TM (3) September 28, 2002 - Landsat 7 ETM+ and (4) October 20, 2013 - Landsat 8 OLI/TIRS. A helpful tool for locating desired imagery in some data source providers is knowing the satellite scene path and row, which in this case is identified as path: 25 and row: 39. Ideally, the images chosen for the change detection will contain cloud conditions of less than twenty percent. The data source, such as United States Geological Survey (USGS) EarthExplorer, will provide information about the cloud conditions for each image, as illustrated in Figure 4.

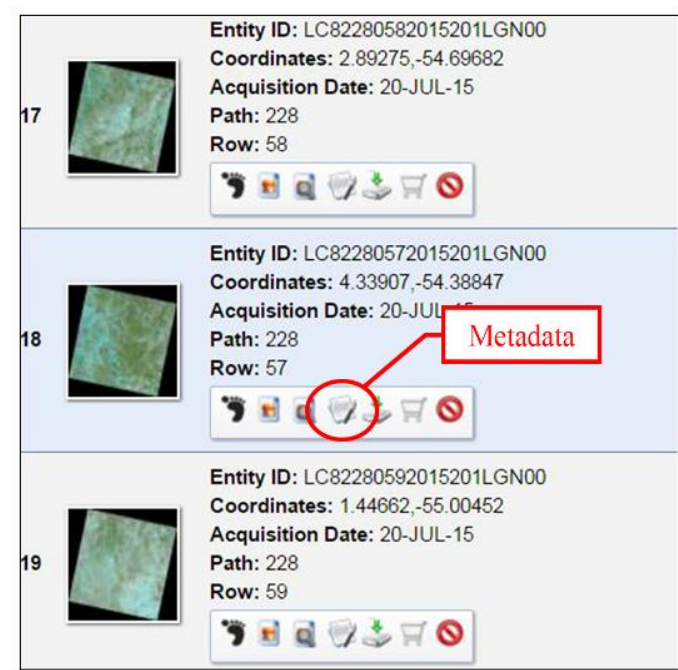

(a)

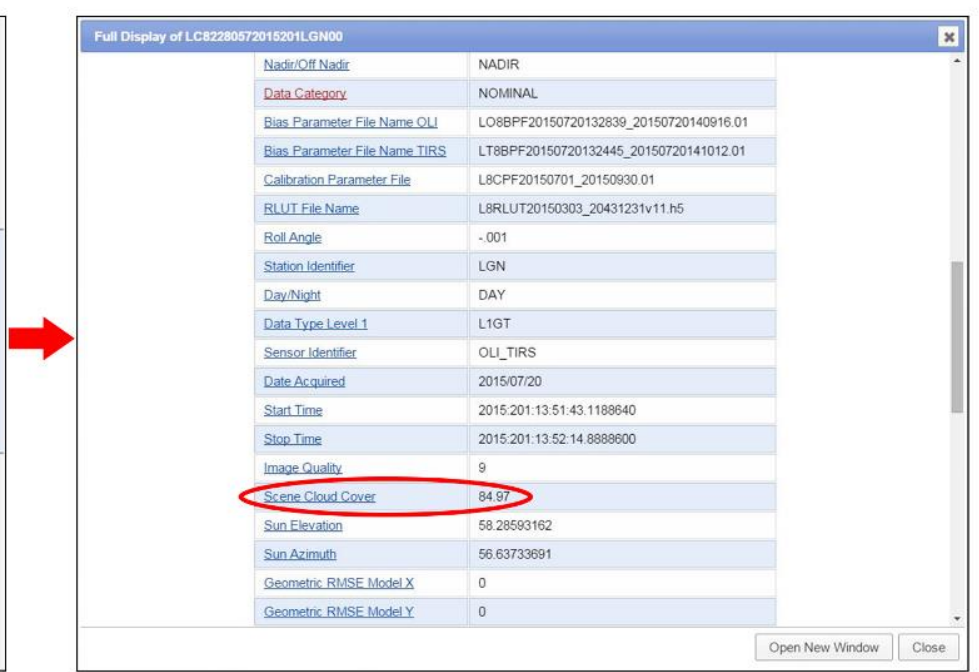

(b)

Figure 4. (a) USGS EarthExplorer image results. (b) Image metadata and information

After obtaining the individual bands of an image dataset from USGS EarthExplorer it was required to create each of the scenes using the Stacklayers tool within ERDAS Imagine as illustrated in Figure 5. ERDAS Imagine is the remote sensing software used within ATCOFA to teach students how to manipulate and use remotely sensed digital data. 


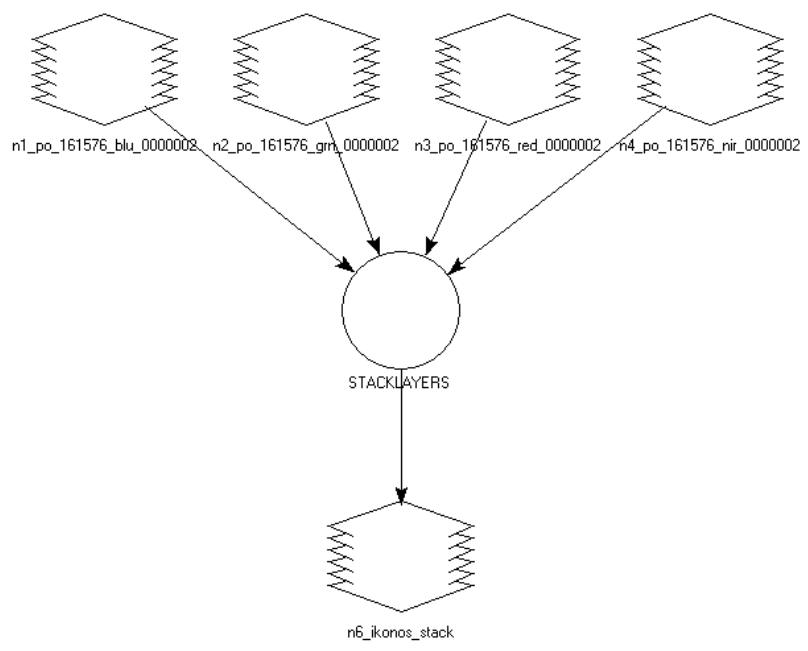

Figure 5. Model Maker view of the Stacklayers tool

During this stage of the image generation it was critical for the student to match the spectral bands between the different image datasets, because the compositions of all satellite datasets do not necessarily share the same band arrangement. For example, Landsat's 5 TM and 7 ETM+ both designate band 1 - blue, band 2 - green, and band 3 red; however, Landsat 8 OLI/TIRS designates band 1 - coastal aerosol, band 2 - blue, band 3 - green, and band 4 red. Therefore the undergraduate student was required to account for the shift in band movement during the layer stacking procedure in order to guarantee spectral consistency over the change detection study period.

\subsubsection{Radiometric and Geometric Correction}

Images obtained through remote sensing may encounter unwanted effects, such as, electronic noise, environmental interference, or sensor system errors. Radiometric correction pertains to correcting systematic errors and enhancing the precision of spectral reflectance, emittance, or back-scattered measurements, on the surface of the Earth.

The first step in performing the radiometric correction was for the student to create subsets of the images that consist of only Nacogdoches and Angelina counties. The next step was to evaluate the metadata and histograms of each of the images. The objective at this stage was to determine and make notation of each of the minimum and maximum pixel values for each band in each of the original master images. The third step consisted of utilizing the spatial model maker to execute the radiometric correction for the imagery. The primary focus of this step was for the student to apply a subtraction of the previously noted minimum pixel values to each of the bands in the images, which is illustrated in Figures 6 through 8.

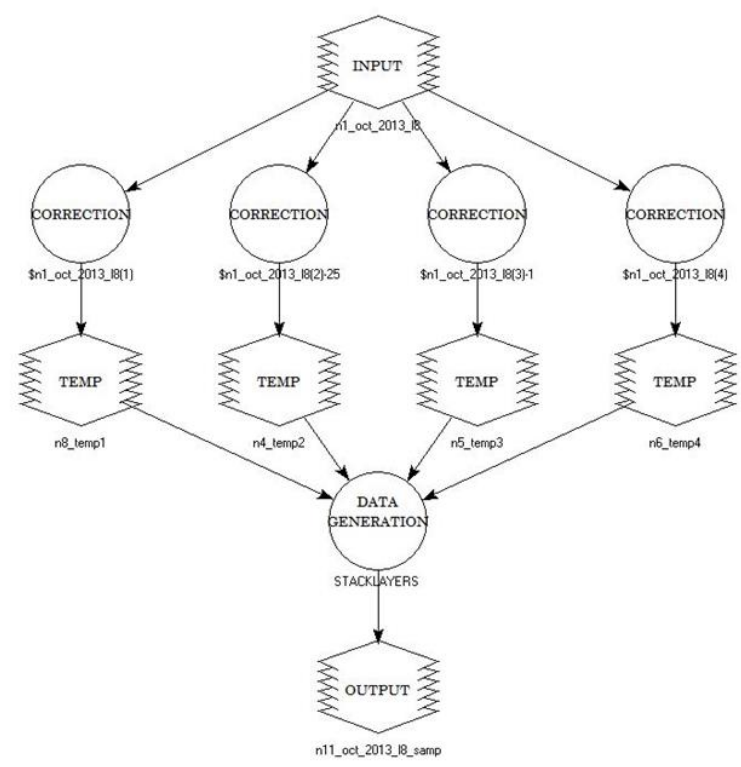

Figure 6. Model Maker view of the radiometric correction workflow process 


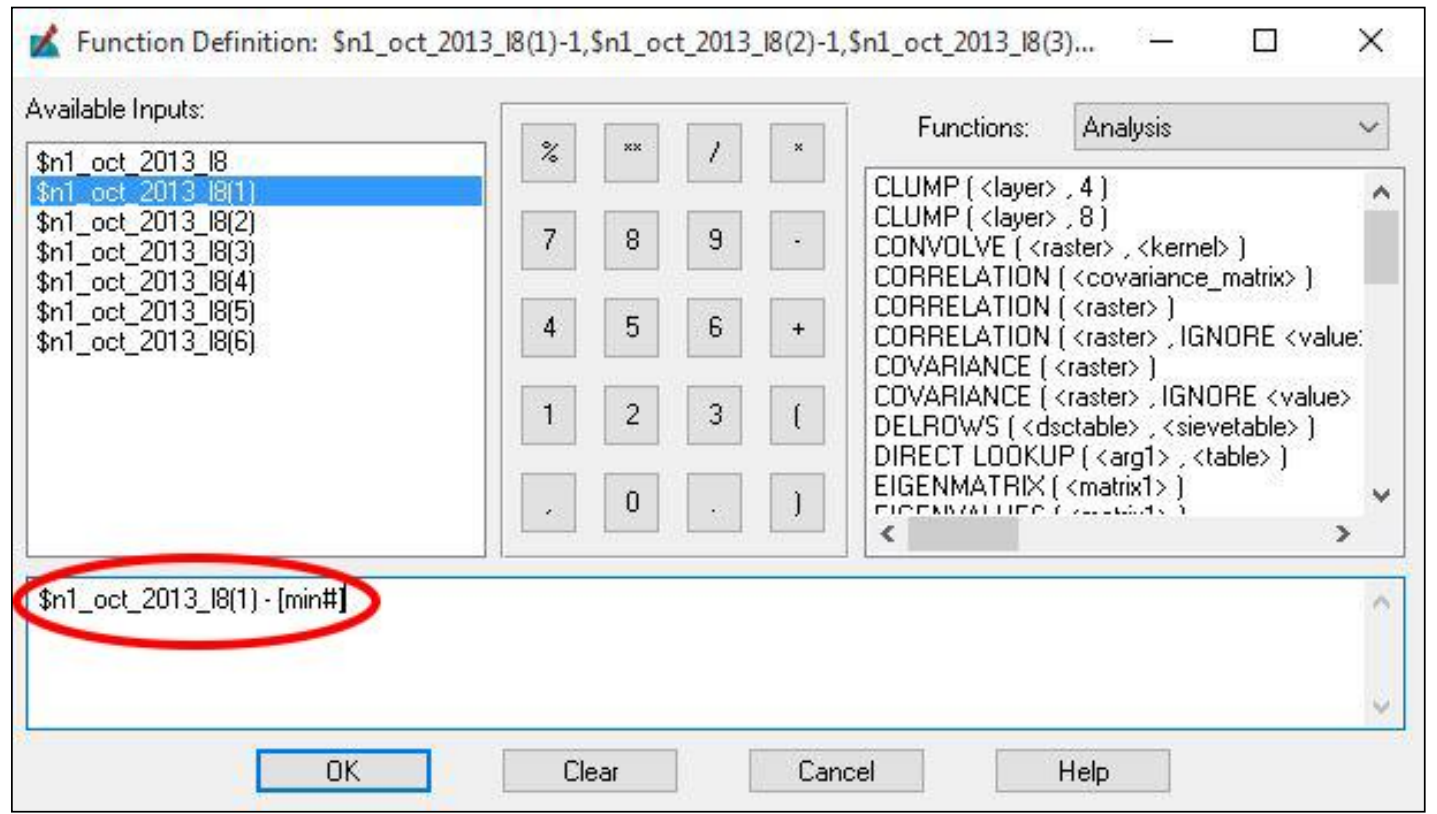

Figure 7. Model Maker radiometric correction function used to subtract the minimum values for each image band

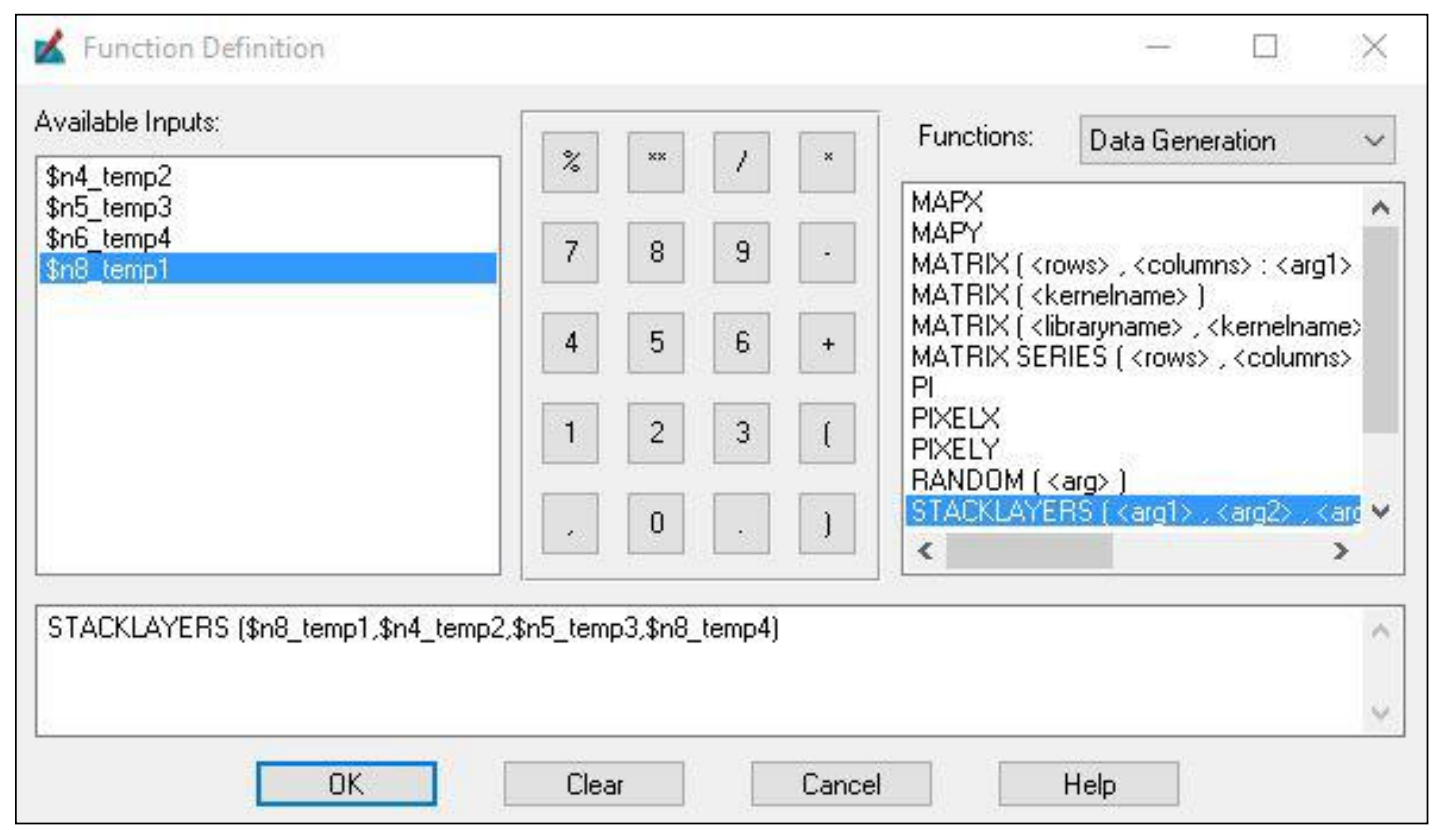

Figure 8. Model Maker radiometric correction data generation function used to stack layers of the temporary subtraction calculations of the minimum pixel values for each image band

It is imperative that each of the images be registered to the same coordinate system in order for the change detection to accurately represent the location of each pixel in the image. Unfortunately, remotely sensed images are not always acquired in their proper geometric $\mathrm{x}, \mathrm{y}$ locations; therefore, preprocessing may be necessary by performing geometric correction on the images in order to properly project individual image elements of the scene to their appropriate planimetric position. However, most reliable sources such as the USGS will have already performed this correction. It was unnecessary for the student to conduct geometric corrections to the remotely sensed imagery in this change detection study.

An additional factor that must be considered is that the spatial resolution of the imagery must coincide; for example, if one of the images is 30-meter and the other is 10-meter, then the 30-meter image must be resampled to a 10-meter grid. All of the images used during this analysis were captured at a 30-meter spatial resolution leaving it unnecessary to resample any of the images. 


\subsubsection{Unsupervised Classification and Change Detection}

The unsupervised classification methodology is commonly derived utilizing satellite imagery and used in thematic mapping. Unsupervised classification methods rely entirely on spectrally pixel-based statistics and integrate no previous knowledge of the characteristics of the subjects being studied. The advantage to performing an unsupervised classification is to automatically convert raw image data into beneficial information, as long as high classification accuracy is achieved (Xie, Sha, \& Yu, 2008).

The unsupervised classification compares the spectral characteristics of digital image pixels, assuming no prior knowledge, and groups them into groups or clusters, based on statistical algorithms. After the computer distributed the image pixels into the initial groups it was then the duty of the student to evaluate, relabel and combine the clusters into their information classes accordingly.

The LUC post classification comparison identifies biophysical changes over time at the same location or locations, on a pixel-by-pixel basis, and maintains consistent anniversary dates for each of the classification processes, as illustrated in Figure 9. The post classification quantities derived during this change detection study are displayed as acreage.

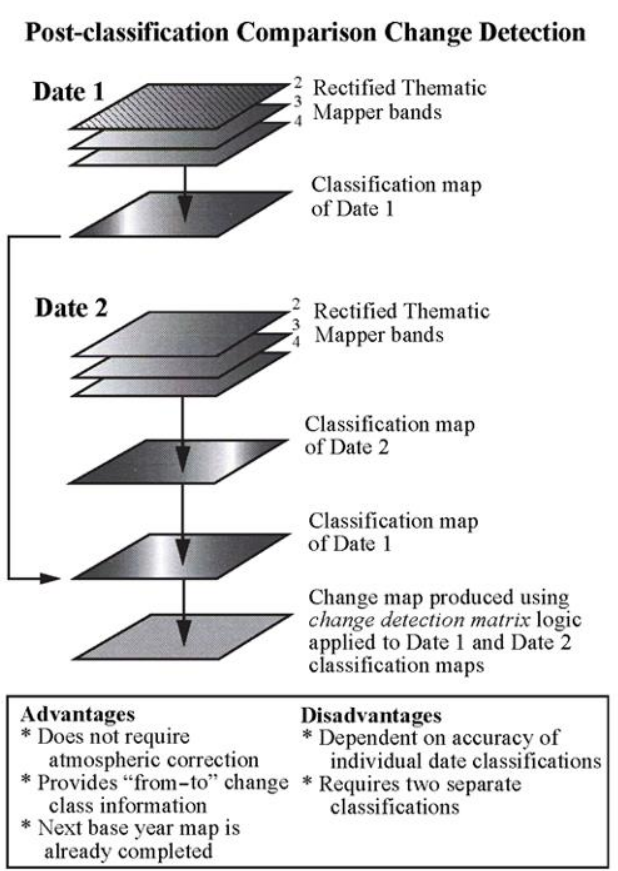

Figure 9. Diagram of post-classification comparison for change detection

The radiometric corrected images were masked by the student using a vector shapefile of Nacogdoches and Angelina counties in order to dispose of all digital data outside of the two-county area. The vector shapefile of Texas county boundaries was obtained from Texas Natural Resources Information System (TNRIS) and processed in ArcGIS for Desktop.

Next, the student initiated the Unsupervised Classification process in ERDAS Imagine. After designating the input raster image and output cluster file locations in the Unsupervised Classification dialog window, the conditions of this study required that the student set the number of classes generated to 100 with a maximum number of 50 iterations and a convergence threshold of $97.5 \%$.

The class types demonstrated in this change detection study were established during a prior study and were derived primarily to focus on observing change in urban development. The classes for this change detection study are (1) water, (2) conifers, (3) mixed forest, (4) deciduous, (5) urban: roads, (6) regeneration, (7) pasture or cropland, (8) urban: mixed, and (9) barren or clearcut.

After the cluster image was generated from the Unsupervised Classification process, it was overlaid with high resolution imagery of the study area in order to determine what each newly created unsupervised class physically represents, and designate which of the nine class types that it belongs to above the two-county raster image for further examination. The student then opened the display attribute table of each image and began the process of 
flickering. This process is done by the student by manually turning the classified image layer on and off with GoogleEarth historic imagery as the reference, through ERDAS GoogleEarth plugin powered by GoogleEarth Pro. Once identified, each of the 100 classes was renamed accordingly and the colors were changed for screen display. One helpful technique used during this visual process was to turn classes already identified and renamed on and off as needed, by changing the opacity level from one to zero or vice-versa.

Once the class identification and renaming process was completed the next step was for the student to recode the 100 classes accessible through the thematic tool menu, under the raster tab menu in ERDAS Imagine. This tool required that the undergraduate student set the input file location to the classified cluster image and designate an output file location. In the meantime, a table displaying the 100 classes allowed the student to transform each renamed class to its appropriate destination class by setting a new value of one through nine representing the nine LCU classes. After completing the reclassify/recode process, the student then compiled the classified maps for Nacogdoches and Angelina counties using the same classification color scheme for each of the four classified maps, illustrated in Figure 10. 


\subsubsection{Nacogdoches and Angelina Counties Classified Maps}

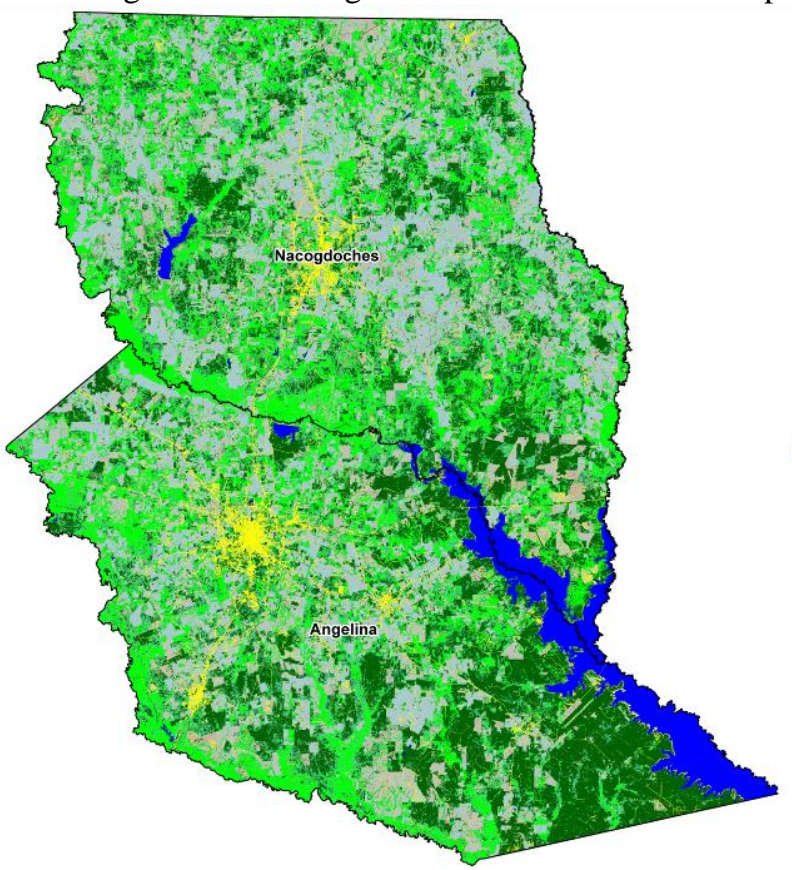

(a)

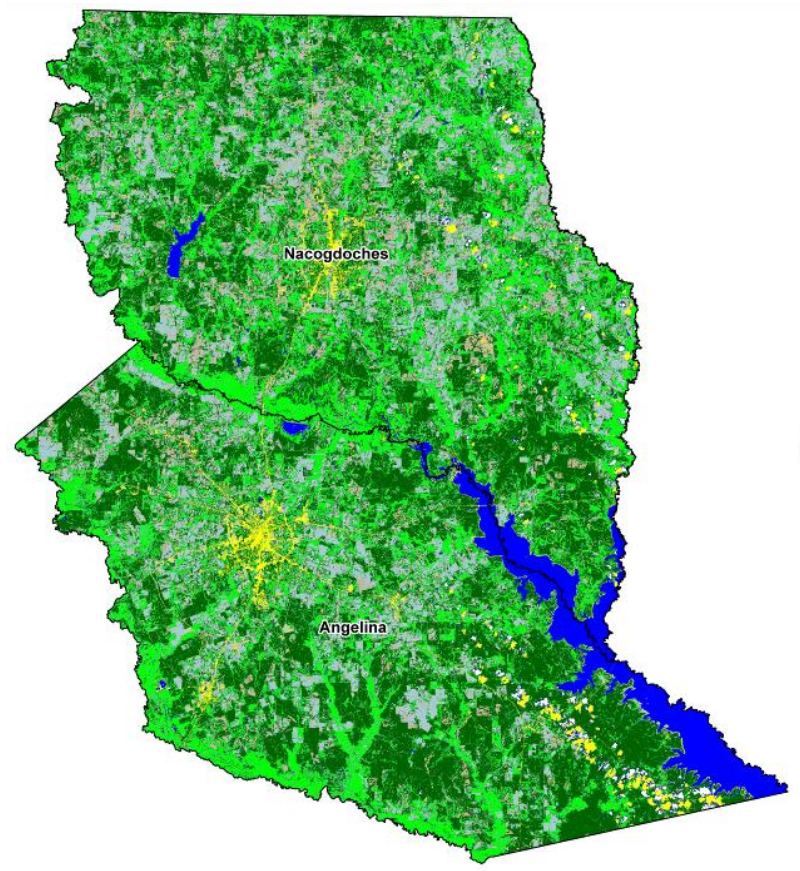

(c)

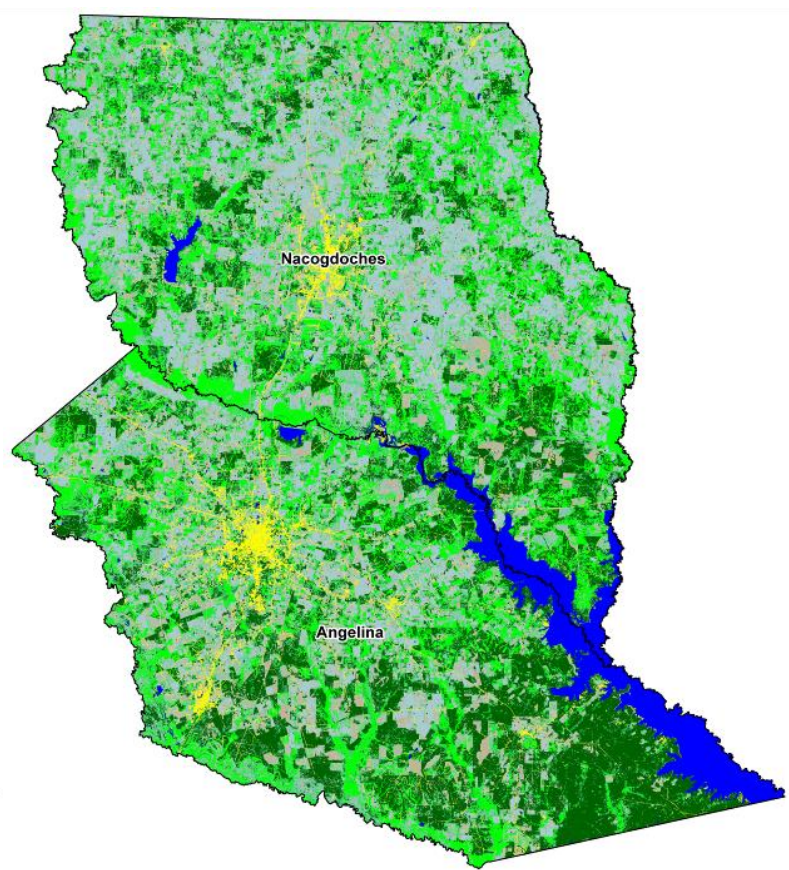

(b)

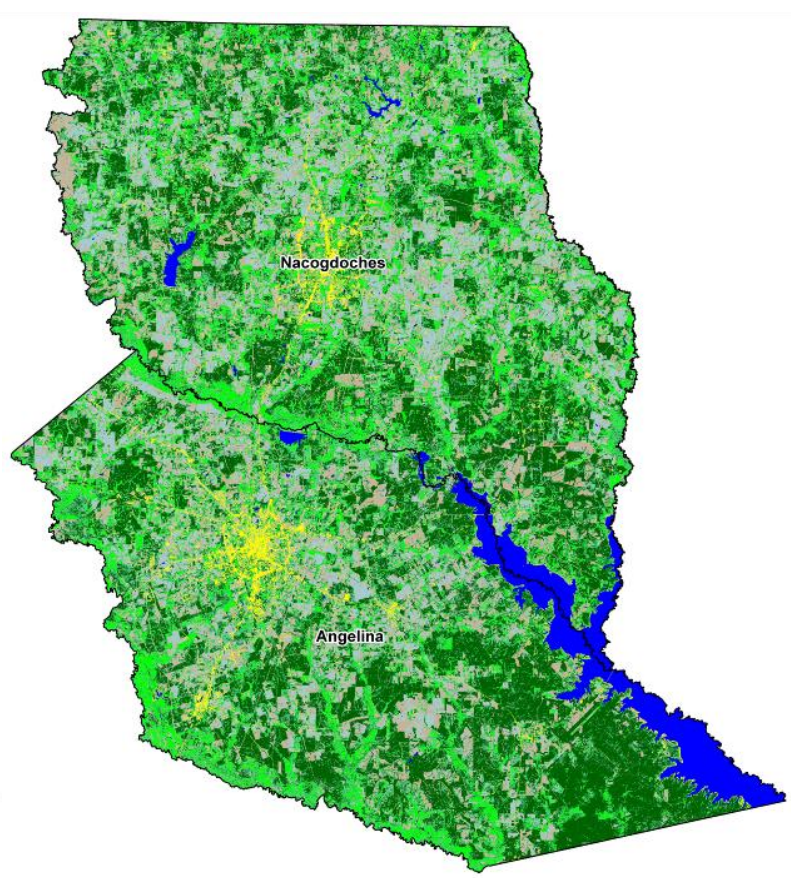

(d)

Figure 10. Map results for Nacogdoches and Angelina counties from the LUC classification process:

(a) 1984 (b) 1992 (c) 2002 and (d) 2013 


\subsubsection{Nacogdoches and Angelina Counties Post-Classification Comparison}

During the post-classification of the change detection the student generated a summary matrix report, which provides "from/to" information for each class from image-to-image. The "from/to" information illustrates values in table format where the change has occurred in each class, and to what alternative class the change has been converted. In ERDAS Imagine the summary matrix report supports the classification results by presenting statistics in a CellArray with several columns, including, class and zone. The class reports the class values of the class file. The zone allows for the number of pixels (Count), area (Area), or percentage of the zone (\% of Zone) that each class occupies in that zone, to be reported. The report data generated in ERDAS Imagine were then exported as plain text files (.dat) and reformatted in Microsoft Excel and presented as two-way tables in this report.

To generate the summary matrix report table from ERDAS Imagine, the student was shown how to navigate to the summary of report matrix tool, under the thematic menu on the raster tab. Within the summary dialog window, the student selected the oldest of the two years classified images for input zone file, followed by selecting the most recent year of the two classified images for input class file. Next, for the output options the student chose the interactive (CellArray) report option and proceeded to generate the report. Once the report was created the student changed the summary by zone setting to acres choosing options, then area units. To transform the summary matrix report into the preferred final format the student selected the summary matrix option from the view menu. Finally, the undergraduate student modified the values in the table of the summary matrix report by changing show, from count to area.

After the summary matrix report was generated in ERDAS Imagine it was then exported to the project file folder in .dat format by right clicking on one of the columns in the report table and choosing the export option. Then the tables were able to be opened in Microsoft Excel allowing the student to generate and finalize the "from/to" information tables for the years in the study. This procedure was completed for each of the change detection study periods totaling four assessments. The first column to the left in the data table is representative of the older year while the first row of the table pertains to the more recent year.

\section{Results}

The output from this change detection study was considered successful by the student and faculty, and the results may provide a wide range of purpose or pertinence for various end-users. It appeared during the classification process that the digital imagery acquired by the Landsat 8 sensor may have had more precise spectral reading of the image pixels, and distributed them more accurately in their clusters. However, some of the preceding satellite sensors faired well in other areas of spectral recognition, grouping other clusters better than the Landsat 8 sensor. The results indicate that the clusters for 100 produced classes may have variation among landscape phenomena due to different Landsat satellites spectral recognition abilities. The results gained by the student, from the change detection LUC classification process, offer great examples of observational data that can be derived through an effective remote sensing evaluation. The figures below show several examples of changes that were detected during the study.

\subsection{Large-Scale Site Results}

The student discovered a number of visual changes at large-scales that occurred during the duration of the change detection study period. The first example illustrated in Figure 11 shows a water reservoir in western Nacogdoches County that altered in shape in size, specifically in the north end of the reservoir during the 2013 scene. Another example illustrated in Figure 12 shows an area, in northern Nacogdoches County, where a water reservoir did not exist at all up until more recent years, which was captured during the 2013 image acquisition. Also, during recent years there were a significant number of what the student determined to be oil production related sites as depicted in the 2013 scene of Figure 13. Figure 14 illustrates a great comparison of one specific study area site that exemplifies some of the linear patterns and precision derived from the Landsat 8 sensor. 


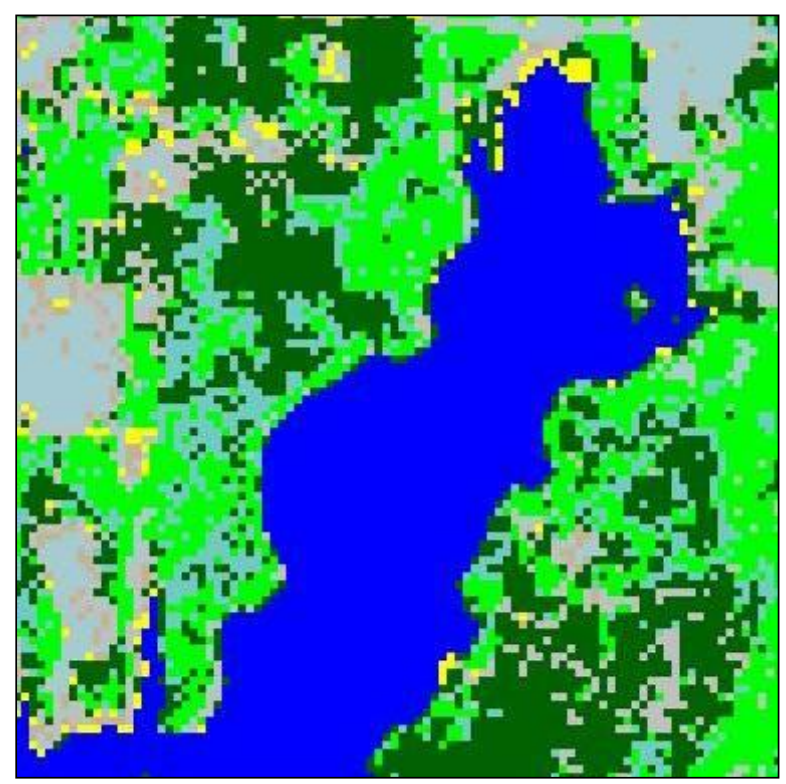

(a)

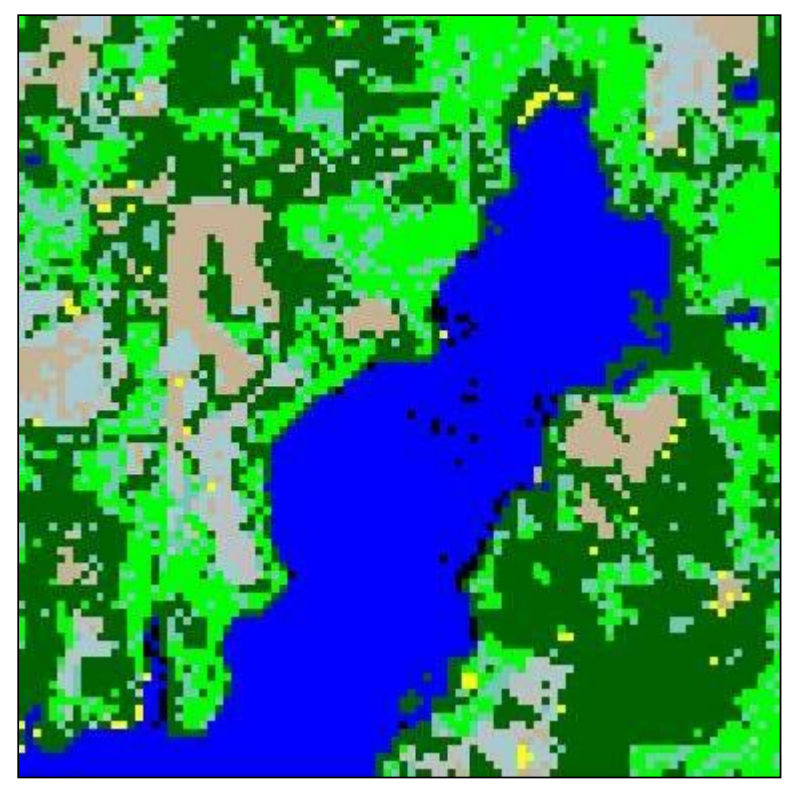

(c)

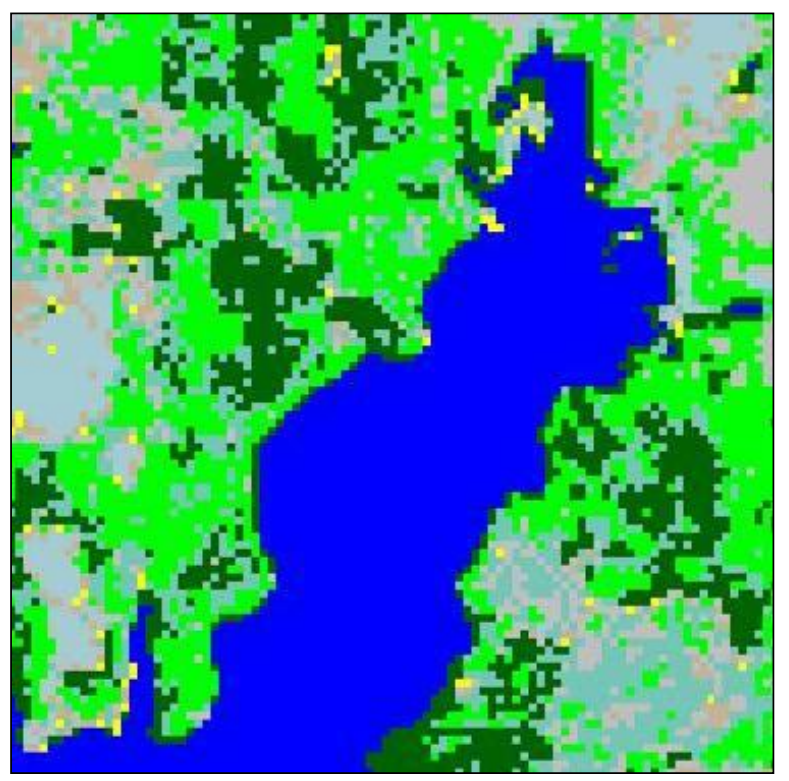

(b)

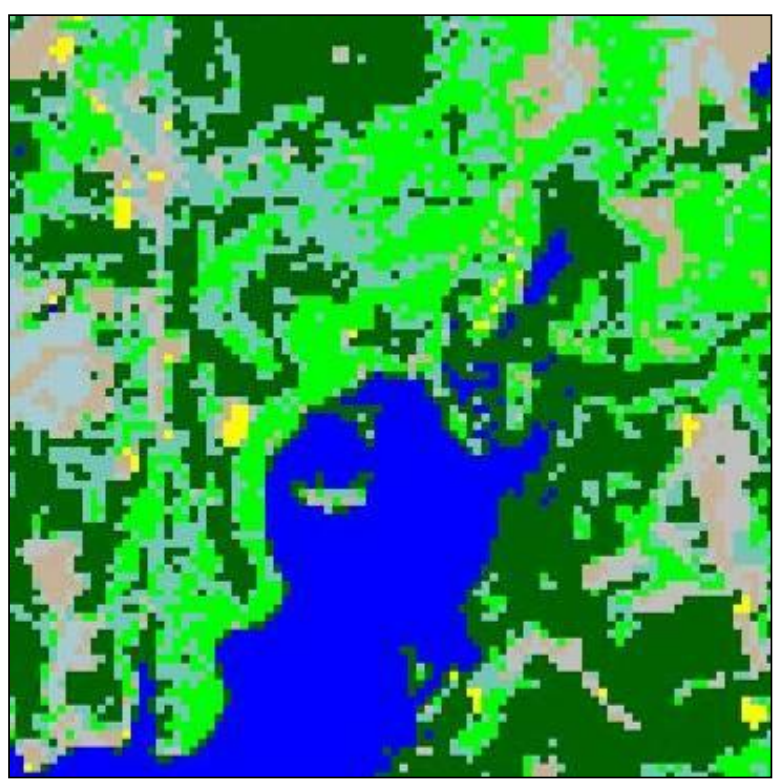

(d)

Figure 11. An example of water level change in a reservoir over the course of the change detection study for (a) 1984, (b) 1992, (c) 2002, and (d) 2013 


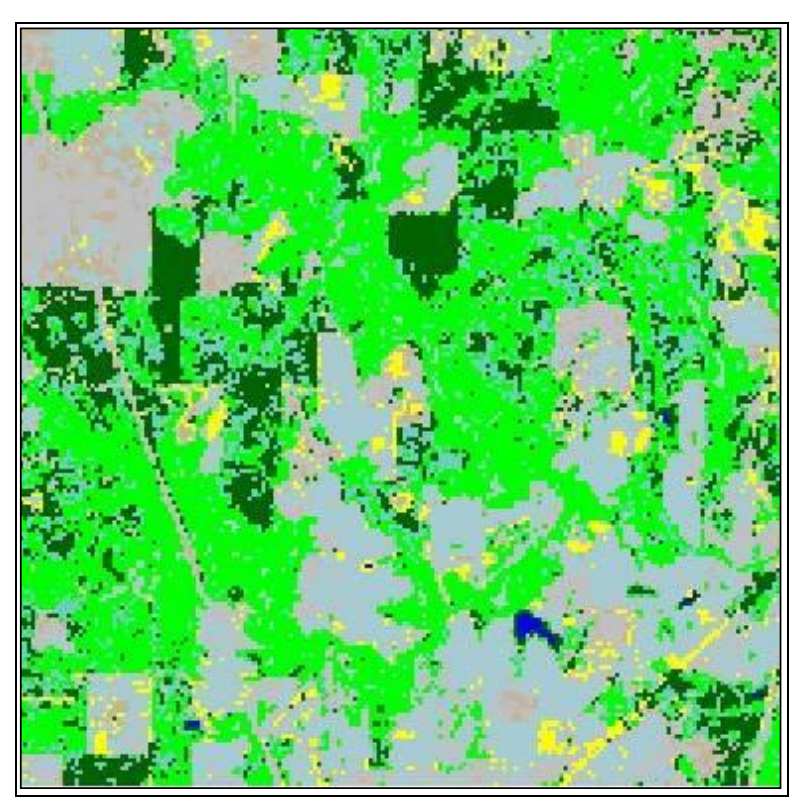

(a)

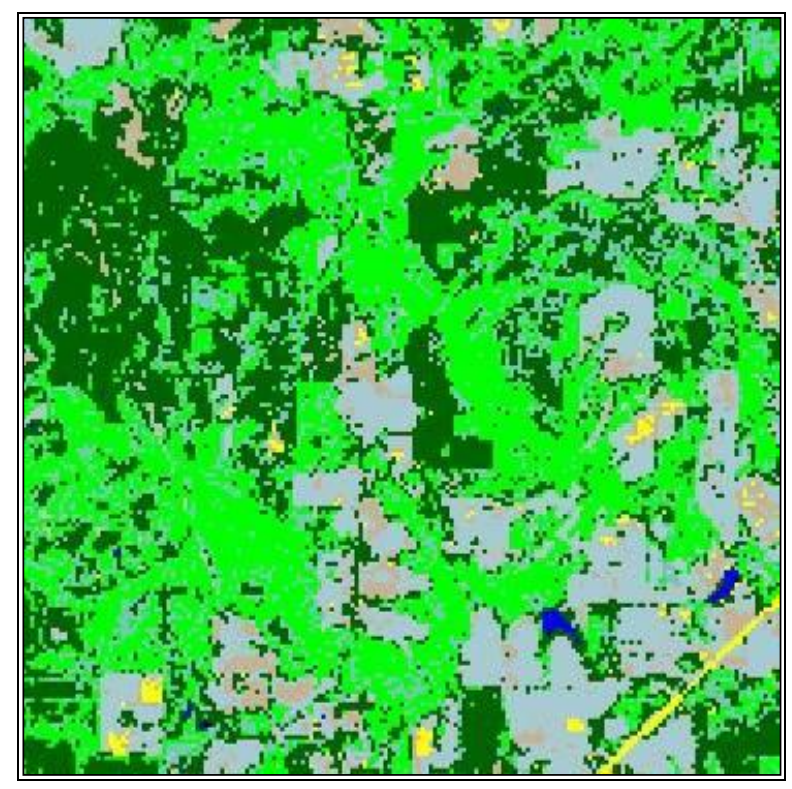

(c)

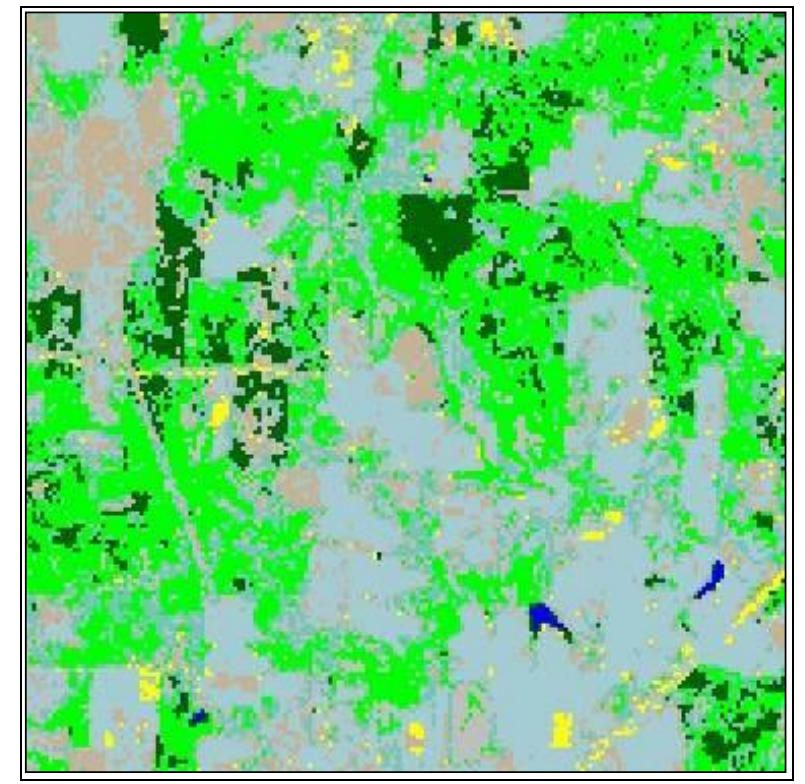

(b)

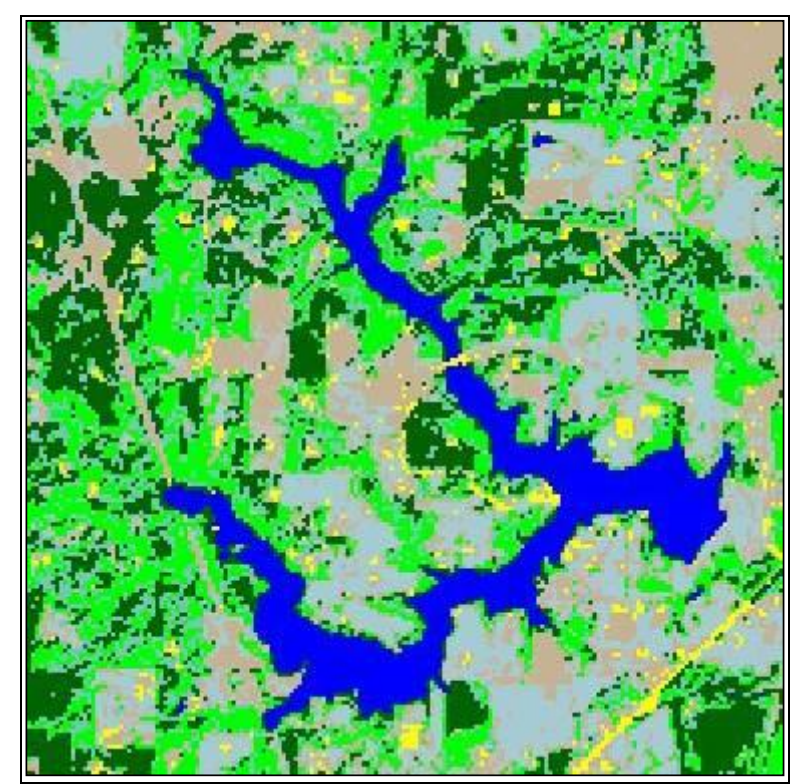

(d)

Figure 12. An area where a water reservoir did not exist up until more recent years (a) 1984, (b) 1992, (c) 2002, and (d) 2013 


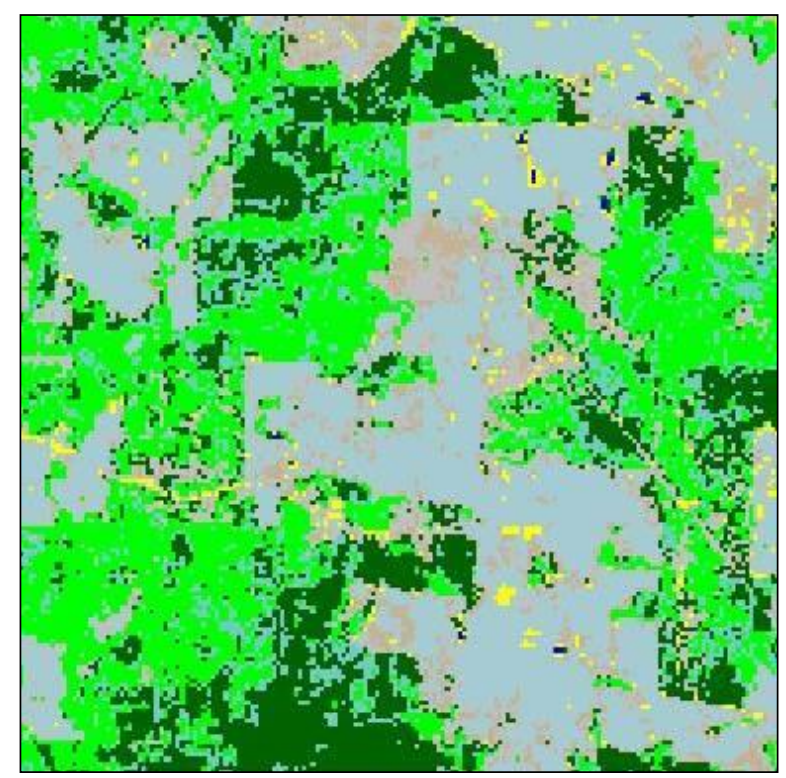

(a)

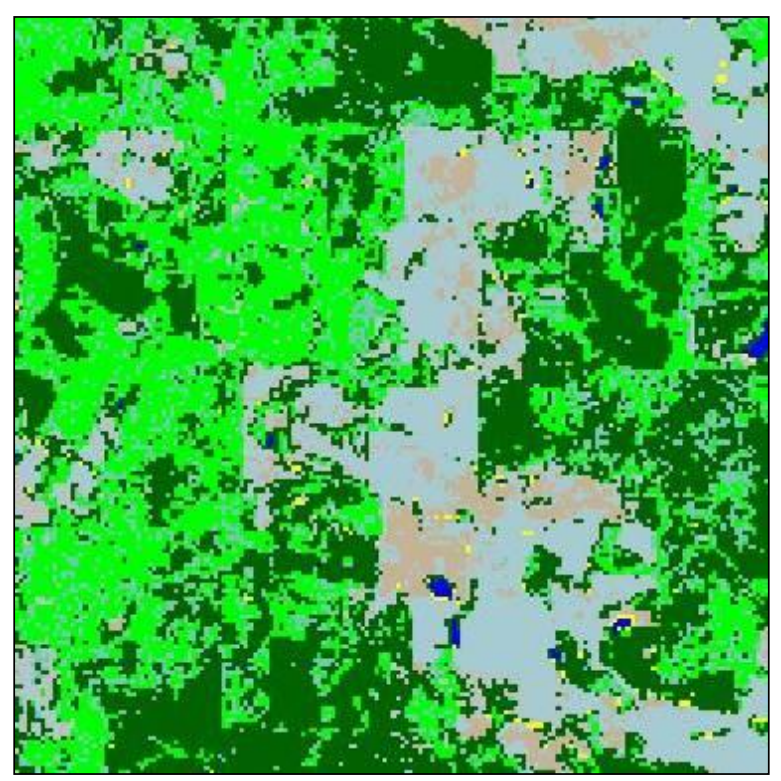

(c)

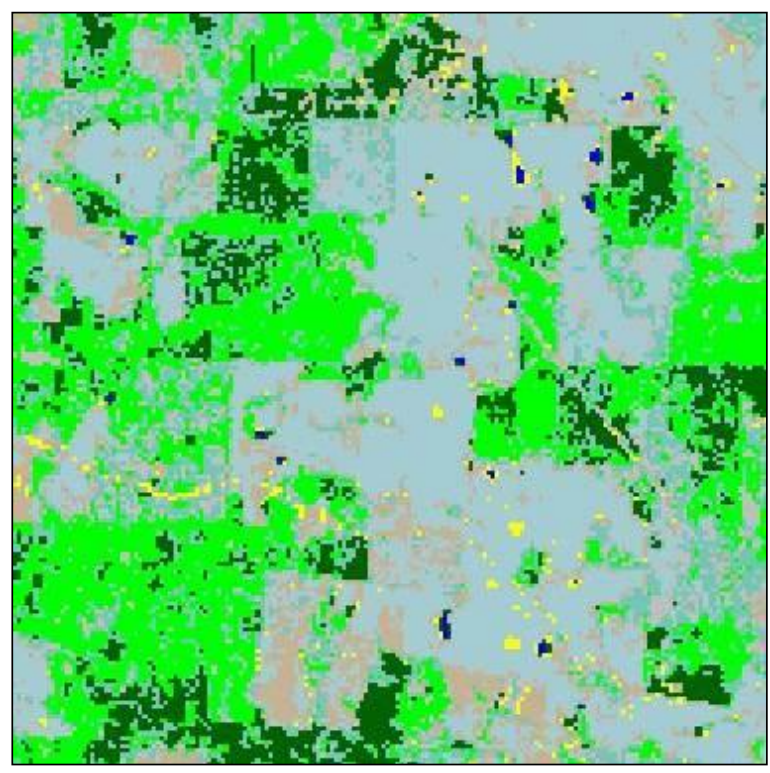

(b)

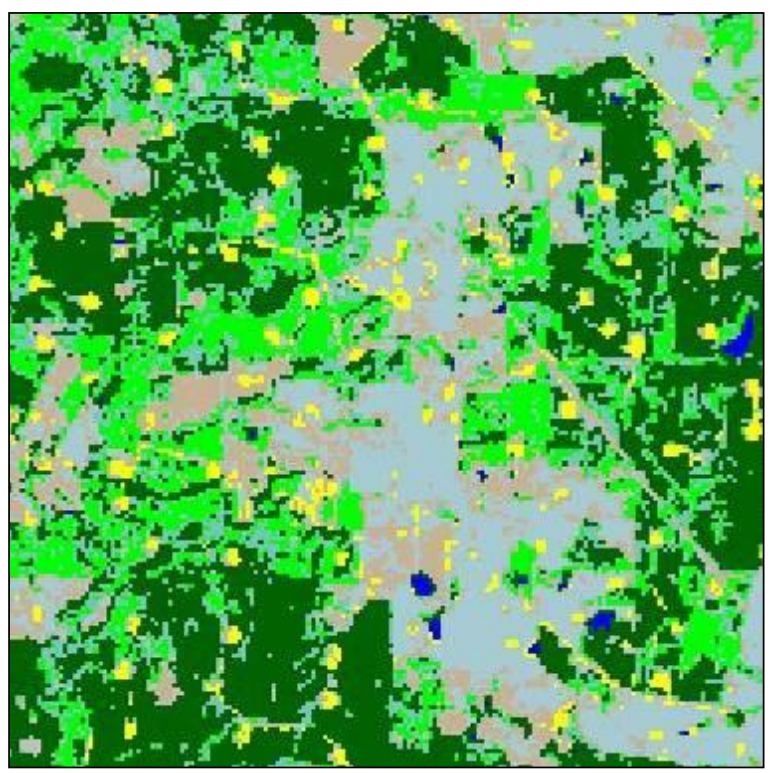

(d)

Figure 13. An area with a significant number of what appears to be oil production related sites found increased in abundance in more recent years (a) 1984, (b) 1992, (c) 2002, and (d) 2013 


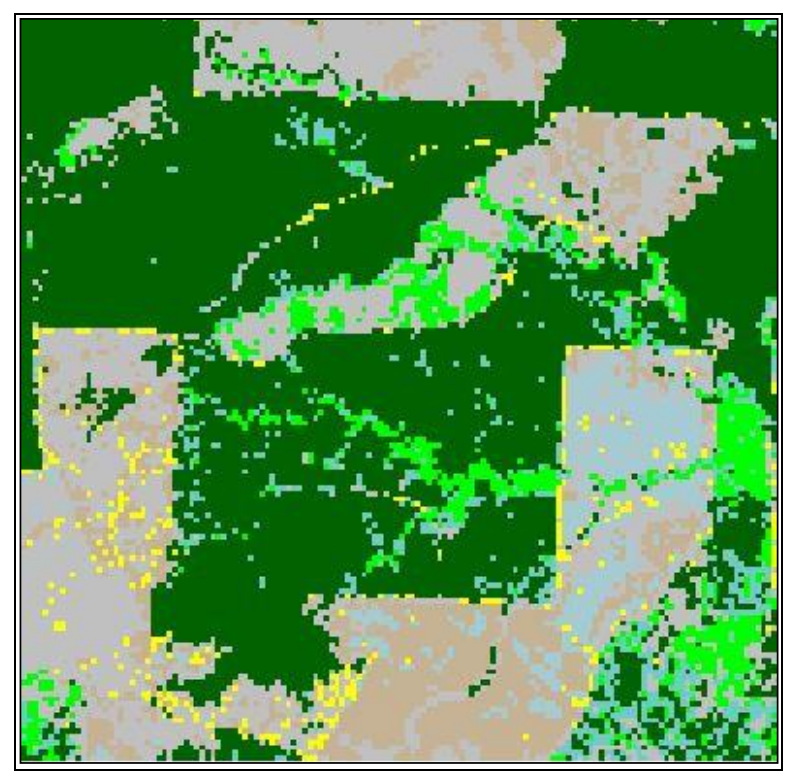

(a)

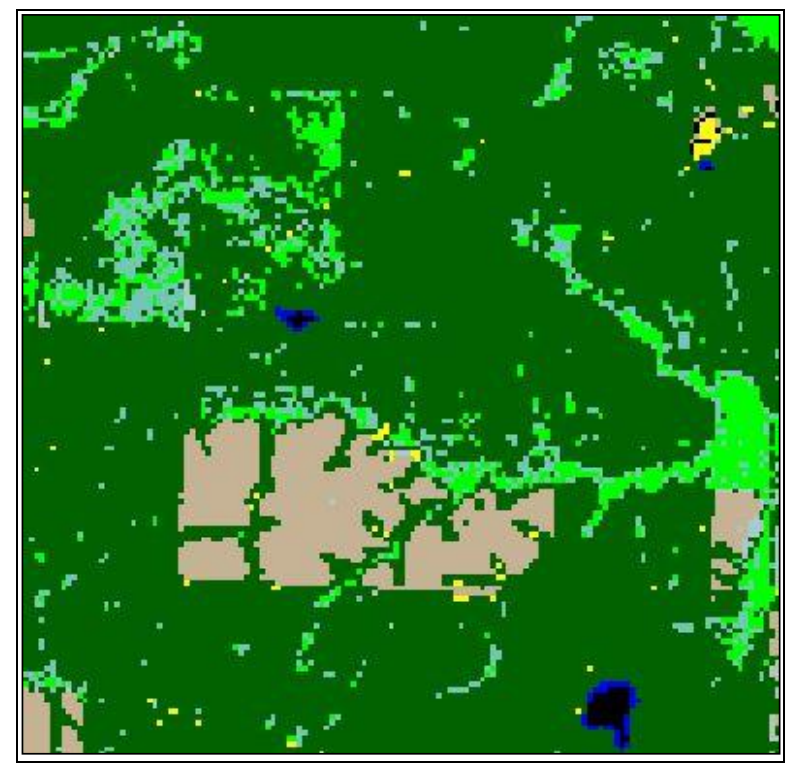

(c)

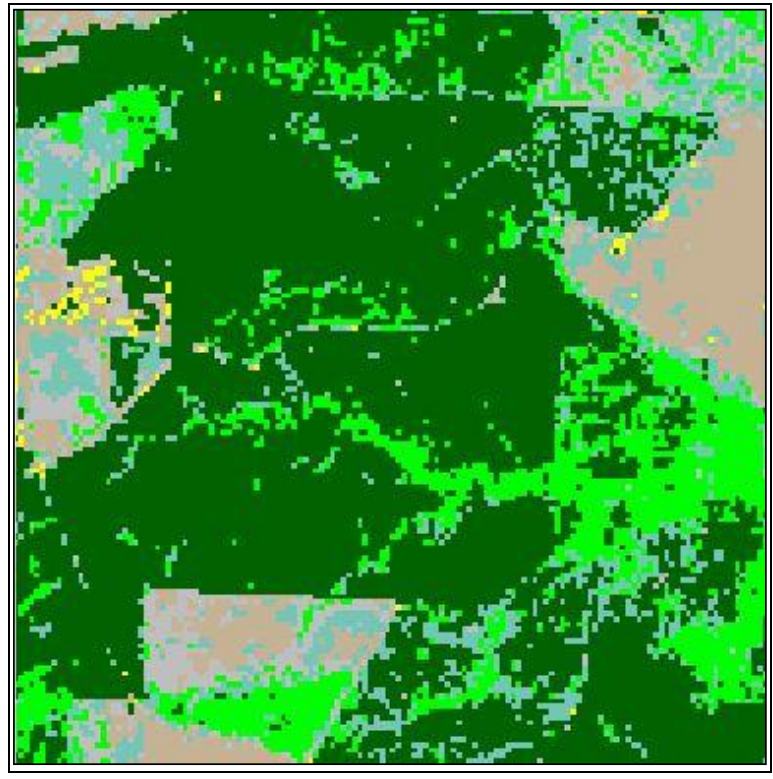

(b)

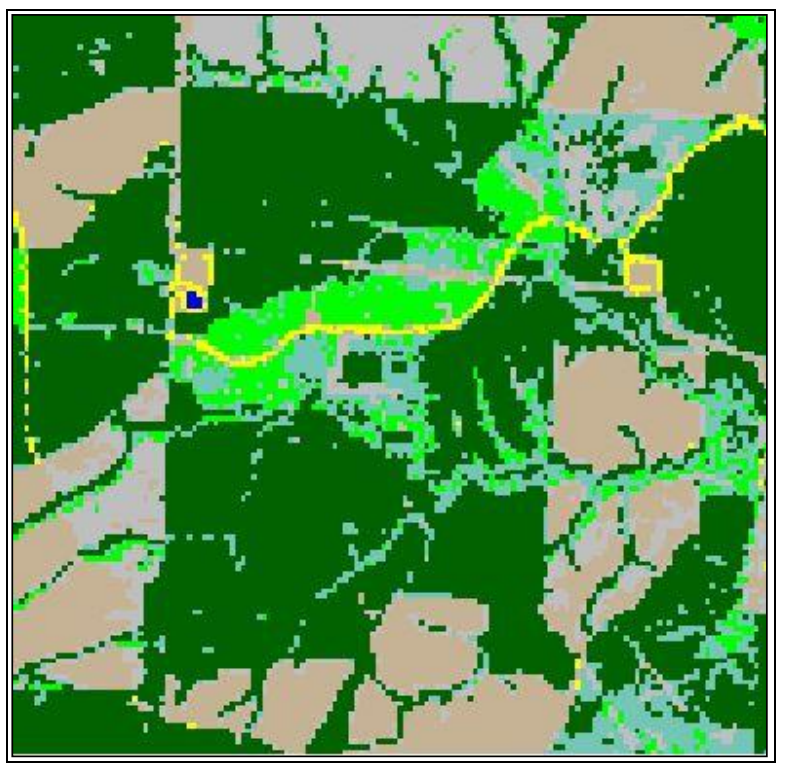

(d)

Figure 14. Comparison of the same site illustrating some of the linear patterns derived from the Landsat 8 satellite sensor (a) 1984, (b) 1992, (c) 2002, and (d) 2013

\subsection{Quantitative Data Results}

The processes that the student followed during this change detection study generated the quantitative values for Nacogdoches and Angelina counties presented in Tables 1 through 4. The tables are the summary matrix report results, derived from the LUC classification process containing the from/to numerical values (acreage). The from/to information represents the numerical quantities where conversions have occurred in each class, during each of the anniversary date change detection analysis. For example, in Table 1 during 1984 there were 29,756.20 acres of conifers that were converted to regeneration. 
Table 1. 1984 to 1992 Nacogdoches and Angelina Counties Post-Classification Results (unit: acre).

\begin{tabular}{|c|c|c|c|c|c|c|c|c|c|c|}
\hline & \multicolumn{10}{|c|}{1992} \\
\hline \multirow{10}{*}{$\begin{array}{l}\text { ऽ } \\
\text { ऽ్- }\end{array}$} & & Water & Conifers & Mixed Forest & Deciduous & Urban: Roads & \begin{tabular}{|l} 
Regeneration \\
\end{tabular} & Pasture/Cropland & Urban: Mixed & Barren/Clearcut \\
\hline & Water & $51,060.30$ & $2,116.09$ & 225.29 & 380.74 & 805.96 & 406.09 & 298.90 & $1,095.74$ & 70.94 \\
\hline & Conifers & 833.54 & $156,403.00$ & $30,768.30$ & $29,108.80$ & $3,670.85$ & $29,756.20$ & $5,002.11$ & $1,866.78$ & $5,014.34$ \\
\hline & \begin{tabular}{|l} 
Mixed Forest \\
\end{tabular} & 79.62 & $43,671.70$ & $28,400.00$ & $54,646.00$ & $3,602.80$ & $29,933.50$ & $14,866.20$ & $1,696.21$ & $4,747.69$ \\
\hline & Deciduous & 41.37 & $34,469.00$ & $34,676.90$ & $153,718.00$ & $1,975.31$ & $30,406.30$ & $8,619.36$ & 753.25 & $3,777.82$ \\
\hline & Urban: Roads & 61.38 & $4,152.56$ & $1,291.00$ & $1,911.93$ & $8,443.00$ & $5,424.43$ & $4,972.75$ & $4,330.03$ & 902.03 \\
\hline & Regeneration & 41.81 & $21,503.10$ & $9,675.51$ & $26,936.90$ & $2,871.56$ & $21,129.50$ & $12,782.40$ & $1,409.98$ & $3,108.41$ \\
\hline & Pasture/Cropland & 54.93 & $7,876.34$ & $3,395.97$ & $8,467.46$ & $6,592.45$ & $25,685.70$ & $124,960.00$ & $1,051.48$ & $7,738.90$ \\
\hline & Urban: Mixed & 42.26 & $1,705.99$ & 521.96 & 455.24 & $3,473.36$ & $1,108.19$ & 888.25 & $2,489.49$ & 593.13 \\
\hline & Barren/Clearcut & 19.57 & $19,368.60$ & $5,306.56$ & $6,779.04$ & $4,743.90$ & $16,439.70$ & $24,592.20$ & $1,639.94$ & $5,885.46$ \\
\hline
\end{tabular}

Table 2. 1992 to 2002 Nacogdoches and Angelina Counties Post-Classification Results (unit: acre).

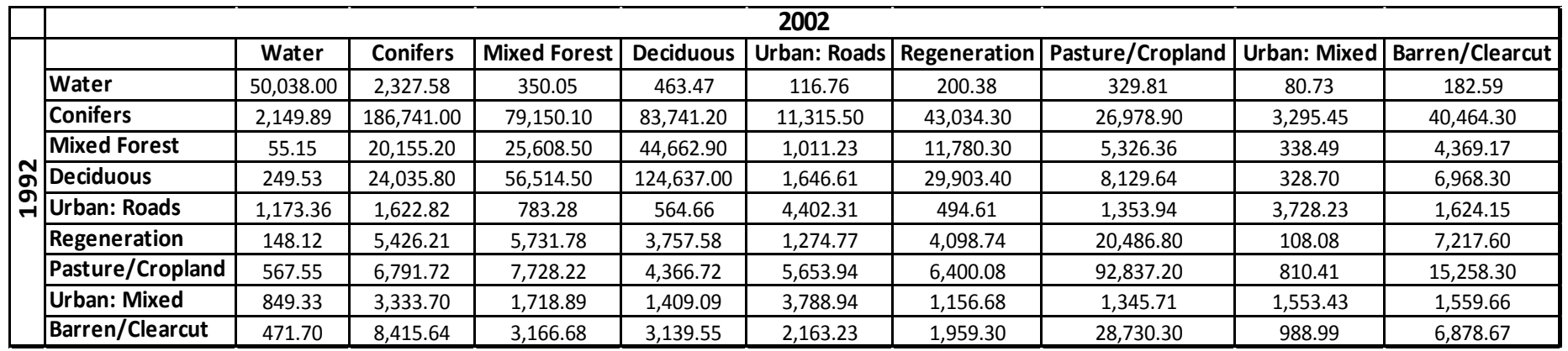

Table 3. 2002 to 2013 Nacogdoches and Angelina Counties Post-Classification Results (unit: acre).

\begin{tabular}{|c|c|c|c|c|c|c|c|c|c|c|}
\hline & \multicolumn{10}{|c|}{2013} \\
\hline & & Water & Conifers & Mixed Forest & Deciduous & Urban: Roads & Regeneration & \begin{tabular}{|l} 
Pasture/Cropland \\
\end{tabular} & Urban: Mixed & Barren/Clearcut \\
\hline \multirow{9}{*}{ ర్ } & Water & $48,211.40$ & 638.94 & 153.01 & 646.28 & 90.96 & 43.37 & 107.42 & 158.12 & 59.38 \\
\hline & Conifers & $3,532.74$ & $264,480.00$ & $35,949.50$ & $44,852.60$ & $2,592.46$ & $7,034.13$ & $9,143.32$ & $4,564.43$ & $11,058.40$ \\
\hline & Mixed Forest & 425.66 & $57,131.20$ & $26,592.20$ & $62,450.70$ & 346.05 & $1,974.64$ & $1,989.32$ & $1,509.62$ & $1,114.42$ \\
\hline & Deciduous & 468.36 & $44,488.10$ & $31,329.40$ & $113,084.00$ & 316.25 & $6,267.31$ & $3,835.42$ & $1,501.83$ & $1,038.58$ \\
\hline & Urban: Roads & 137.66 & $4,588.23$ & 377.85 & 692.32 & $3,385.52$ & 333.59 & $2,071.83$ & $2,113.42$ & 953.41 \\
\hline & Regeneration & 290.00 & $41,673.90$ & $6,605.57$ & $12,667.80$ & 920.72 & $4,102.74$ & $4,997.21$ & $1,707.99$ & $1,665.74$ \\
\hline & Pasture/Cropland & 241.30 & $9,732.67$ & $2,715.00$ & $3,258.08$ & 741.24 & $11,507.80$ & $79,080.10$ & 894.03 & $22,088.70$ \\
\hline & Urban: Mixed & 326.70 & $3,130.21$ & 479.71 & 835.76 & $5,582.56$ & 464.58 & $3,680.86$ & $2,396.97$ & $2,685.86$ \\
\hline & Barren/Clearcut & 455.47 & $51,007.60$ & $9,105.07$ & $13,925.00$ & $1,771.60$ & $16,521.50$ & $35,508.70$ & $1,869.01$ & $15,249.60$ \\
\hline
\end{tabular}

Table 4. 1984 to 2013 Nacogdoches and Angelina Counties Post-Classification Results (unit: acre).

\begin{tabular}{|c|c|c|c|c|c|c|c|c|c|c|}
\hline & & & & & & 2013 & & & & \\
\hline & & Water & Conifers & Mixed Forest & Deciduous & Urban: Roads & Regeneration & Pasture/Cropland & Urban: Mixed & Barren/Clearcut \\
\hline & Water & $47,423.30$ & $1,040.59$ & 219.95 & 902.70 & 243.75 & 304.46 & 312.91 & 366.28 & 60.49 \\
\hline & Conifers & $1,888.35$ & $175,068.00$ & $49,290.90$ & $79,368.30$ & $6,314.90$ & $45,281.20$ & $19,335.70$ & $3,038.58$ & $8,094.73$ \\
\hline & Mixed Forest & 280.22 & $37,270.00$ & $22,212.10$ & $59,866.00$ & $2,931.16$ & $19,867.40$ & $7,772.48$ & $1,513.84$ & $2,832.87$ \\
\hline$\infty$ & Deciduous & 443.46 & $29,912.60$ & $23,363.70$ & $97,861.50$ & $3,313.68$ & $27,089.00$ & $16,689.20$ & $1,607.69$ & $2,961.19$ \\
\hline न & \begin{tabular}{|l|} 
Urban: Roads \\
\end{tabular} & 300.90 & $2,435.00$ & 834.20 & $1,285.22$ & $3,522.73$ & $2,254.64$ & $1,614.14$ & $2,028.46$ & 465.03 \\
\hline & \begin{tabular}{|l} 
Regeneration \\
\end{tabular} & 375.18 & $16,408.10$ & $6,505.94$ & $14,737.40$ & $3,802.29$ & $17,325.00$ & $10,511.90$ & $1,629.49$ & $3,582.34$ \\
\hline & Pasture/Cropland & 315.58 & $5,632.37$ & $2,767.48$ & $7,155.78$ & $4,465.69$ & $17,019.90$ & $86,982.00$ & $1,135.55$ & $4,964.08$ \\
\hline & Urban: Mixed & 487.49 & $2,517.29$ & 900.25 & $1,595.46$ & $4,650.28$ & $2,262.42$ & $3,409.31$ & $2,759.70$ & $1,051.48$ \\
\hline & Barren/Clearcut & 720.34 & $20,982.10$ & $8,167.01$ & $19,631.20$ & $6,934.72$ & $28,885.50$ & $50,354.60$ & $2,253.30$ & $7,826.52$ \\
\hline
\end{tabular}




\section{Conclusion}

Using remote sensing technology a senior undergraduate student under the direction of GIS faculty learned how to generate natural resources management maps that could be used for observation and decision making purposes. The remote sensing methodologies and techniques demonstrated by the senior spatial science undergraduate student using ERDAS Imagine and ESRI ArcMap 10.3 GIS software reinforces that these approaches can provide an essential avenue of remote sensing analysis for natural resource management assessments. The results from the study and the students' ability to acquire multifaceted remote sensing information validate the hands-on instruction methodology employed in the remote sensing and spatial science curriculums within ATCOFA at SFA. The results also reinforce ATCOFA's mission by empowering students with the capability of employing sophisticated remote sensing technology to accurately quantify, qualify, map, and monitor natural resources.

The student learned that a remote sensing user performing a project of this complexity must maintain a considerably high level of organization in order to maintain certainty and consistency among the project database files. For example, during the duration of this project the student experienced scenarios that required digitally intermediate data, which may have been created a matter of weeks or months ago, to be revisited on occasion.

During the classification process the student was able to use the services of GoogleEarth Pro as an aid in visual interpretation. By using the historical imagery features of GoogleEarth the student could zoom to single pixel scale and evaluate aerial photography or satellite imagery corresponding to the specific location of interest and consider that information while determining the correct class for that cluster. However, the GoogleEarth historical imagery did not cover all of the areas entirely, leaving the service unusable for some areas in the study region. Additional limitations experienced by the student with the GoogleEarth imagery was that the image resolution widely ranged in quality and the time of year the images were captured. The GoogleEarth service did provide assistance during the visual interpretation, however, the limitations experienced by the student certainly did contribute frustration to what may eventually offer an advantageous aid for a remote sensing analyst during visual interpretation.

In order to further guarantee the precision of this change detection study, the student would need to continue the study by performing an accuracy assessment, which would generate statistical errors from the classification process. The accuracy assessment would require the student to expand the threshold of the study to allow for the timely process of traveling to several hundred locations in the study area and make observations regarding the physical features at each sample site. The observations would then be calculated in association with the classification process and provide the additional data needed in order to generate the statistical error matrix.

During this remote sensing project the student demonstrated an excellent workflow regimen for generating data that can be very useful for city planners, analysts, and natural resources management entities. This LUC classification process illustrated one of the many benefits of remote sensing and exemplified how efficiently that the discipline can aid in scientifically examining the changes in natural resource landscapes.

\section{Acknowledgements}

This research was supported by McIntire Stennis Cooperative Research funds administered by the Arthur Temple College of Forestry and Agriculture.

\section{References}

Bullard, S.H., Stephens Williams, P., Coble, T., Coble, D.W., Darville, R., \& Rogers, L. (2014). Producing "Society-ready" Foresters: A Research-Based Process to Revise the Bachelor of Science in Forestry Curriculum at Stephen F. Austin State University. Journal of Forestry, 112(4), 354-360. http://dx.doi.org/10.5849/jof.13-098

Campbell, J. B., \& Wynne, R. H. (2011). Introduction to Remote Sensing. New York, New York: The Guilford Press.

He, T., Sun Y., Xu J., Wang X., \& Hu, C. (2014). Enhanced land use/cover classification using support vector machines and fuzzy k-means clustering algorithms. Journal of Applied Remote Sensing, 8(1), http://dx.doi.org/10.1117/1.JRS.8.083636

Hung, I., Williams J.M., Kroll J.C., \& Unger, D.R. (2004). Forest Landscape Changes in East Texas from 1974 to 2002. $4^{\text {th }}$ Southern Forestry and Natural Resources GIS Conference, Athens, Georgia, December 16-17, 64-75.

Jensen, J.R. (2005). Introductory Digital Image Processing: A Remote Sensing Perspective, ( $3^{\text {rd }}$ Ed.). Saddle River, New Jersey. 
Kulhavy, D.L., Unger, D.R., Hung I., \& Douglass, D. (2015). Integrating hands-on undergraduate research in an applied spatial science senior level capstone course. International Journal of Higher Education, 4(1), 52-60. http://dx.doi.org/10.5430/ijhe.v4n1p52

Kulhavy, D.L., Unger, D.R., Williams, H.M., \& Jamar, D.R. (2015). Teaching hands-on urban forestry health assessment using the resistograph and the CTLA method. Journal of Studies in Education, 5(1), 139-149. http://dx.doi.org/10.5296/jse.v5i1.7150

McBroom, M., Bullard, S., Kulhavy, D., \& Unger, D. (2015). Implementation of collaborative learning as a high-impact practice in a natural resources management section of freshman seminar. International Journal of Higher Education, 4(4), 64-72. http://dx.doi.org/10.5430/ijhe.v4n4p64

Owojori, Akinwale O. "Land use and land cover change associated with the growth of Nacogdoches and Lufkin, Texas from 1984 to 2002." Thesis. Stephen F. Austin State University, 2003. Print.

Rosson, J.F. (2000). Forest resources of east Texas, 1992. USDA, Forest Service, Southern Research Station: Resource Bulletin. SRS-53. Asheville, NC.

Unger, D.R. (2014). Validating one-on-one GPS instruction methodology for natural resource area assessments using forestry undergraduate students. Higher Education Studies, 4(1), 94-102. http://dx.doi.org/10.5539/hes.v4n1p94

Unger, D.R., Kulhavy, D.L., Hung, I., \& Zhang, Y. (2014). Quantifying natural resources using field-based instruction and hands-on applications. Journal of Studies in Education, 4(2), 1-14. http://dx.doi.org/10.5296/jse.v4i2.5309

Xie, Y., Sha, Z., \& Yu M. (March 2008). Remote sensing imagery in vegetation mapping: a review. Journal of Plant Ecology, 1(1), 9-23. http://dx.doi.org/10.1093/jpe/rtm005 